\title{
A fixed nitrous oxide/oxygen mixture as an analgesic for trauma patients in emergency department: study protocol for a randomized, controlled trial
}

Lu-Lu Gao ${ }^{1 \dagger}$, Li-Shan Yang ${ }^{2 \dagger}$, Jun-Jun Zhang ${ }^{1+}$, Yi-Ling Wang ${ }^{1+}$, Ke Feng ${ }^{2}$, Lei Ma ${ }^{2}$, Yuan-Yuan Yu², Qiang Li ${ }^{2}$,

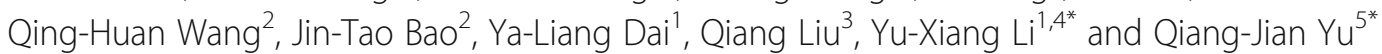

\begin{abstract}
Background: Acute pain is always the most common complaint in Emergency Department admissions and options for analgesia are limited. Nitrous oxide/oxygen possess many properties showing it may be an ideal analgesic method for the Emergency Department; it is quick-acting, well-tolerated, and does not mask signs and symptoms. The aim of this study is to evaluate the safety and analgesic effect of the fixed nitrous oxide/oxygen mixture for trauma patients in a busy emergency environment.

Methods: The randomized, double-blind, prospective, placebo-controlled study will be carried out in the Emergency Department of General Hospital of Ningxia Medical University. The target research objects are trauma patients who present to the Emergency Department and report moderate to severe intensities of acute pain. A total of 90 patients will be recruited and randomly assigned into the treatment and control group. The treatment group will receive conventional pain treatment plus nitrous oxide/oxygen mixture and the control group will receive conventional pain treatment plus oxygen. Neither patients, nor investigators, nor data collectors will know the nature of the gas mixture in each cylinder and the randomization list. Outcomes will be monitored at baseline(T0), 5 min (T1), and 15 min (T2) after the beginning of intervention and at 5 min post intervention (T3) for each group. The primary outcome is the level of pain relief after the initial administering of the intervention at T1, T2, and T3. Secondary outcomes include adverse events, physiological parameters, total time of the gas administration, satisfaction from both patients and healthcare professionals, and the acceptance of patients.
\end{abstract}

Discussion: Our previous studies suggested that a fixed nitrous oxide/oxygen mixture was an efficacious analgesic for the management of burning dressing pain and breakthrough cancer pain. The results of this study will provide a more in-depth understanding of the effect of this gas. If this treatment proves successful, it could help to generate preliminary guidelines and be implemented widely in trauma patients with pain in Emergency Departments.

Trial registration: Chinese Clinical Trial Register, ChiCTR-INR-16007807. Registered on 21 January 2016.

Keywords: Trauma, Analgesia, Acute pain, Nitrous oxide

*Correspondence: li_yuxiang@163.com; yuja910315@163.com

'Lu-Lu Gao, Li-Shan Yang, Jun-Jun Zhang and Yi-Ling Wang contributed equally to this work.

'School of Nursing, Ningxia Medical University, 1160 Shengli Street, Yinchuan

750004, China

${ }^{5}$ Department of Pharmacology, Pharmaceutical Institute of Ningxia Medical

University, 1160 Shengli Street, Yinchuan 750004, China

Full list of author information is available at the end of the article

(c) The Author(s). 2018 Open Access This article is distributed under the terms of the Creative Commons Attribution 4.0 International License (http://creativecommons.org/licenses/by/4.0/) which permits unrestricted use, distribution, and reproduction in any medium, provided you give appropriate credit to the original author(s) and the source, provide a link to the Creative Commons license, and indicate if changes were made. The Creative Commons Public Domain Dedication waiver (http://creativecommons.org/publicdomain/zero/1.0/) applies to the data made available in this article, unless otherwise stated. 


\section{Background}

Despite there are extensive research on the etiology of pain, barriers to pain management, advanced analgesia approach, and evidence-based guidelines for the pain management such as the World Health Organization three-step analgesic ladder, acute pain remains a common complaint observed in the Emergency Department (ED) with a high prevalence of up to $90 \%$ [1-3]. Over the past decades, emergency health workers have documented that the prevalence of pain undertreatment is high. Numerous studies demonstrated that $60-80 \%$ of patients reported pain on admission to the $\operatorname{ED}[2,4,5]$. It continues to be a challenge for emergency healthcare givers to treat oligoanalgesia or undertreatment of pain [6]. A prospective cross-sectional study assessed 525 ED patients' experiences and satisfaction with pain management and reported that only half of patients received analgesics even though $63 \%$ suffered with severe pain. The average time to analgesic administration was almost $2 \mathrm{~h}$ and the percentage of patients who received analgesics within $1 \mathrm{~h}$ after arrival was only $29 \%$ [7]. In a retrospective medical record study, Wilson and Pendelton [8] found that no more than half of patients admitted to the ED for acute pain were treated with analgesics during hospitalization. Of these, nearly $70 \%$ of patient waited $>1 \mathrm{~h}$ and $>40 \%$ waited $>2 \mathrm{~h}$ for analgesics. In another prospective study conducted in the ED of a teaching hospital in Central Africa, nearly 50\% of the patients did not receive prescribed analgesia before definitive surgical treatment, including most patients with severe pain [9]. These observed results are consistent with previous studies $[10,11]$. Taking into account previous reports, the results of these studies show that the practice of oligoanalgesia in the ED is a global phenomenon, partially because emergency health workers fail to fully assess or perceive the patient's pain intensity [9]. All in all, the percentage of patients who receive any type of analgesia and pain relief is still deficient.

Efforts to treat acute pain are priorities for ED healthcare to consider. Patients expect analgesia rapidly in the ED, which is not met in many ED [12]. Several reasons have been related to poorly managed pain. First, the failure assessment or lack of skills to assess patients' pain is a main predicting factor of pain treatment deficiency. The physicians' underestimation of pain can be circumvented by using the pain assessment scales [13-15]. Second, in our institution, no analgesic guideline exists to help the physician prescribe analgesics for patients in need and no effort was made to influence physicians' orders for analgesia [4]. Physicians are also worried about concealing, delaying, or obscuring diagnosis [11, 16], although there is poor evidence of this. There are still many myths and misconceptions about opioids, addiction, and tolerance $[17,18]$. We likewise have a limited ability to monitor the cardiopulmonary function of opiates in the ED. Third, a crowded ED setting and insufficient ED staff affect acute pain assessment and reassessment [19]. It is probable that busy healthcare professionals pay less attention to complaints of painful conditions. In fact, pain management is not a priority in assessing and resuscitating these patients traditionally. Other factors including gender, race, age, education, language, and cultural and socioeconomic backgrounds also play important roles in the disparity of treatment [20-23].

However, patients with unrelieved pain lead to a stress response consisting of increased heart rate and blood pressure, impaired immune function, systemic vascular resistance, and altered release of neuroendocrine, pituitary, and other hormones [24]. These responses could limit patients' recovery from injury, resulting in longer hospitalization, higher readmission rates, and more frequent outpatient visits. These factors may lead to lower rates of ED patient satisfaction and an increase in medical cost [25]. Hence, acute pain management should be a priority for us to consider and we have several reasons to search for safe and universal analgesics.

Nitrous oxide/oxygen is a self-administered inhaled gas reserved in a pre-prepared cylinder. Its analgesic effect has been known for nearly two centuries [26]. It has few side effects, all of which disappear after termination of exposure to the gas. There is no need for an endovenous procedure. The patients' self-sustained facemasks lower the risk of overdose as the patients' level of consciousness control their ability to maintain the gas flow [27]. Therefore, it is safe and non-invasive [28]. Owing to its low solubility in blood and not bound to proteins, it possesses the properties of rapid onset (no more than $2 \mathrm{~min})$ and is quickly reversible after discontinuation (< $1 \mathrm{~min}$ ). As a result, nitrous oxide does not obscure the signs and symptoms that may be necessary for subsequent damage or disease definitive diagnosis. It is reported that the mixture will play the same role as of a 15-mg dose of morphine given intramuscularly [29]. These properties also suggest that nitrous oxide/oxygen may be an ideal analgesic for ED use. Taking these advantages into account, we hypothesize that a fixed concentration of nitrous oxide/oxygen mixture (Patent no. ZL 20131 0053336.X) can provide superior analgesic effects for trauma patients with acute pain in the ED.

\section{Methods/design}

Aim

The primary aim of the current study is to determine the clinical analgesic effect of the fixed nitrous oxide/ oxygen mixture on trauma patients with acute pain when compared with the control group. It is measured by pain relief level. Secondary objectives of this trial include: 
1. Evaluating the clinical use safety of the fixed gas by physiological parameters and adverse effects.

2. Assessing the satisfaction of both patients and healthcare workers with pain treatment.

3. Investigating patients' acceptance for the new analgesia method.

\section{Study design}

This is a single-center, prospective, randomized, doubleblind, placebo-controlled, two-arm, superiority study. It was designed to test the analgesic effect and safety of inhaling premixed nitrous oxide/oxygen use in adult trauma patients with moderate to severe acute pain. This protocol was drafted using the SPIRIT guidelines [30] (see Additional file 1) and following the checklist of the Consolidated Standards of Reporting Trials (CONSORT) statement (see Additional file 2). The clinical trial was reviewed and approved by the Ningxia Medical University Ethics Committee. This study has been registered at Chinese Clinical Trial Registry (registration no. ChiCTR-INR-16007807). The whole study design is provided in Fig. 1. Additionally, a SPIRIT figure for the schedule of enrolment, interventions, and assessments is presented in Fig. 2.

\section{Study setting}

This study will be carried out in the ED of General Hospital of Ningxia Medical University. This institution is an urban, public, 4500-bed, tertiary-care teaching hospital located in Northwest China, with an ED census of 179,117 annually.

\section{Study participants}

All trauma patients who present to the ED will be invited to participate. The specific inclusion criteria are: patients who speak Chinese; aged $\geq 18$ years; report moderate to severe intensity of acute pain upon admission (defined as a pain score $\geq 4$ according to the Numerical Rating Scale [NRS]); are able to take deep breaths to use the self-managed device; are willing to participate in the study and sign informed consent. Patients are ineligible if they have considered contraindications to using the premixed gas (intracranial hypertension, recent ophthalmic surgery, epilepsy, unconsciousness, pneumothorax / hemothorax, facial traumas, intestinal obstruction, pulmonary embolism, emphysema, sinusitis, and retinal detachment [17]). Other exclusion criteria are: recent receipt of analgesics within $6 \mathrm{~h}$; life-threatening situations or instability of clinical vital signs; pregnancy; individuals

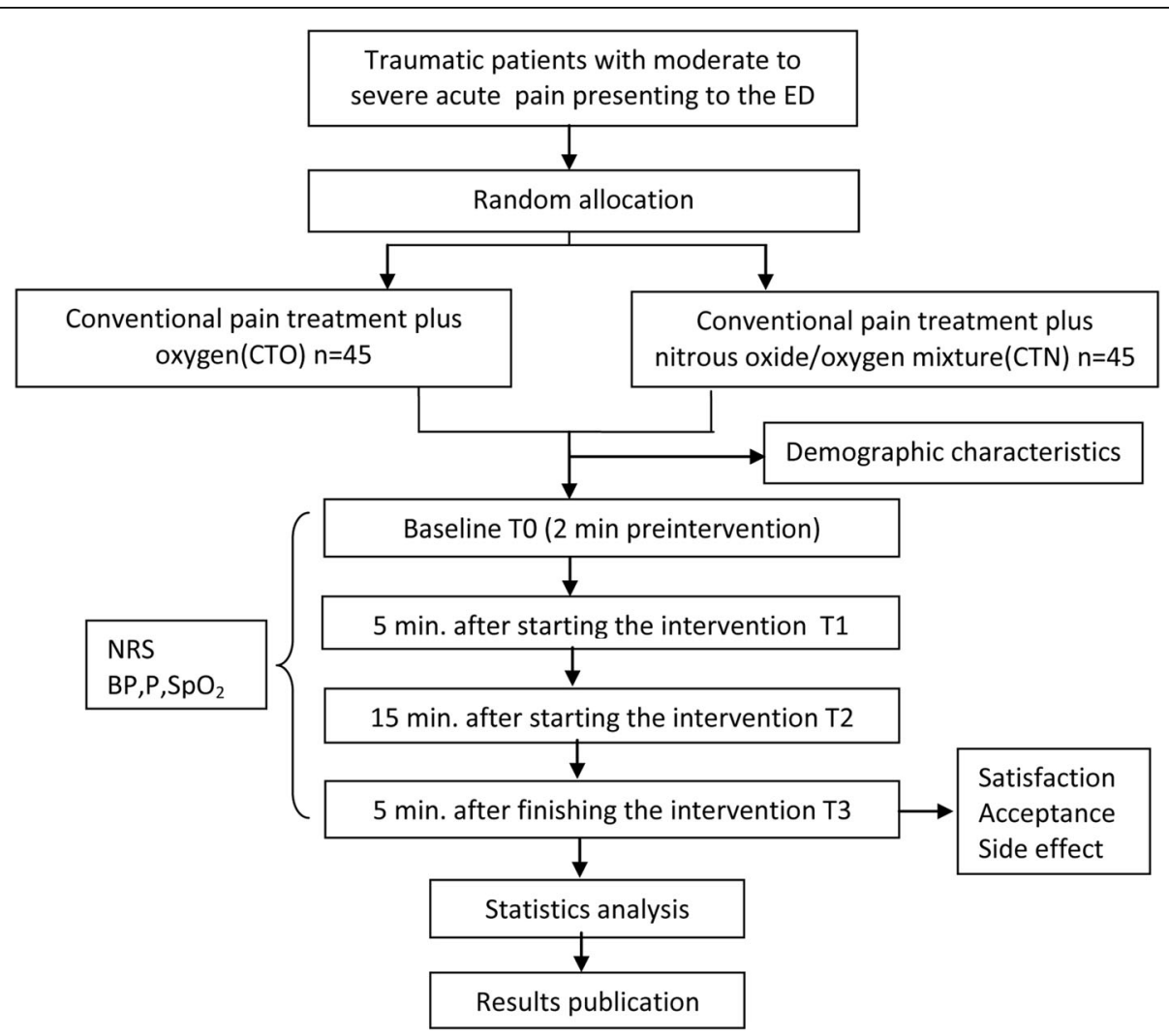

Fig. 1 Study design. NRS numerical pain rating scale, BP blood pressure, HR heart rate, $\mathrm{SpO}_{2}$ oxygen saturation, CTO conventional pain treatment plus oxygen, CTN conventional pain treatment plus nitrous oxide/oxygen mixture 


\begin{tabular}{|c|c|c|c|c|c|}
\hline & \multicolumn{5}{|l|}{ Study period } \\
\hline & Enrolment & \multicolumn{4}{|c|}{ Post-allocation } \\
\hline TIMEPOINT & $\begin{array}{c}\text { Trauma } \\
\text { patients } \\
\text { with } \\
\text { acute pain }\end{array}$ & T0 & $\mathrm{T} 1$ & T2 & $\mathrm{T3}$ \\
\hline \multicolumn{6}{|c|}{ ENROLMENT } \\
\hline $\begin{array}{l}\text { Eligibility } \\
\text { screen }\end{array}$ & $x$ & & & & \\
\hline $\begin{array}{c}\text { Informed } \\
\text { consent }\end{array}$ & $x$ & & & & \\
\hline Allocation & $x$ & & & & \\
\hline \multicolumn{6}{|c|}{ INTERVENTIONS } \\
\hline $\begin{array}{c}\text { Treatment } \\
\text { group }\end{array}$ & & & $x$ & $x$ & \\
\hline Control group & & & $x$ & $x$ & \\
\hline \multicolumn{6}{|c|}{ ASSESSMENT } \\
\hline $\begin{array}{l}\text { Numerical } \\
\text { pain } \\
\text { rating scale }\end{array}$ & $x$ & $x$ & $x$ & $x$ & $x$ \\
\hline Blood pressure & & $x$ & $x$ & $x$ & $x$ \\
\hline $\begin{array}{c}\text { Oxygen } \\
\text { saturation }\end{array}$ & & $x$ & $x$ & $x$ & $x$ \\
\hline Heart rate & & $x$ & $x$ & $x$ & $x$ \\
\hline Satisfaction & & & & & $x$ \\
\hline Acceptance & & & & & $x$ \\
\hline Side effect & & & $x$ & $x$ & $x$ \\
\hline
\end{tabular}

Fig. 2 SPIRIT figure: schedule of enrolment, interventions, and assessments

in police custody; or individuals included in another study.

All participating clinicians will be associate chief physicians, will have worked in the ED for $>5$ years, and will be willing to participate in and receive training from the originator who conceived and designed the protocol. In this trial, two fixed clinicians who meet all the above criteria will be included.

\section{Interventions}

All patients entering the ED will receive regular assessments by the clinician. The patients who meet all pre-specified inclusion and exclusion criteria will be introduced to the study. Investigators will explain the purpose, benefits, and potential risks of the study in detail to the patients. If the patients agree to participate in this study, they will be asked to sign an informed consent form and then be recruited. Subsequently, the relevant treatment will be carried out immediately. During the implementation of the intervention, the patients are randomly allocated to inhale either a fixed concentration of premixed nitrous oxide/oxygen or oxygen through a specially designed facemask with a one-way valve. The treatment group will receive nitrous oxide/oxygen mixture in addition to conventional pain treatment and the control group will receive oxygen in addition to conventional pain treatment. In this study, the oxygen cylinder is designed exactly the same as the nitrous oxide cylinder and oxygen is safe and readily available in the selected ED. We chose oxygen plus conventional pain treatment as a comparator to ensure the full consistency between treatment group and control group and the double-blind design. Gas inhalation will be administered continuously up to a maximum inhalation time of 15 min. Practitioners will be permitted to use other pain management forms in accordance with patients' pain intensity after finishing the intervention. The trained investigator will successively include participants until they reach the target sample size and the project manager will assign participants to interventions according to the randomization list.

Generally, both nitrous oxide/oxygen and oxygen are considered safe interventions with no severe side effects for the participants. If side effects occur (e.g. dizziness, nausea) during the implementation of nitrous oxide/oxygen, they are usually short-lived and mild [28]. If any 
undesirable events occur or the participant requests to cease the intervention they received, the investigator can discern whether the trial will be continued. In all cases, the reason for discontinuation will be documented by the data collector.

There are many strategies to improve the adherence of the intervention. Before the start of the intervention, investigators will detail the duration of the intervention, the method of using the device, possible adverse effects, and give psychological support to participants. During the treatment, the patients' physiological parameters are monitored and patients are asked if they feel uncomfortable or not. If they are uncomfortable, this is address immediately to ensure the ongoing safety of patients is accomplished. Adherence of intervention protocols will be ascertained by accomplishment of the intervention. We planned to develop a Supervision Adherence Form (SAF) for this trial to enable collation of patients' adherence to facilitate reporting.

\section{Randomization, allocation concealment, and blinding}

All participants will be randomly allocated into the intervention or control group in a ratio of 1:1. The randomization list of each ED patient will be generated by a computer, which is calculated by a statistical expert from the Faculty of Medical Statistics and Epidemiology, Ningxia Medical University. A sealed envelope will be used to store the randomization schedule which will be restricted in a dedicated research office to maintain confidentiality. In order to make sure of "double-blind" conditions, no data collectors or investigators have access to the data distribution. Only the project manager who will be responsible for gas distribution can consult this information. Ningfeng Oxygen Company packages the two gas mixtures in strictly identical-looking gas cylinders, one containing nitrous oxide/oxygen and the other oxygen. Therefor, all the gas cylinders will be identified only with a label (A or B). Patients given the letter A will be treated using a canister with the appropriate letter containing premixed nitrous oxide/oxygen. Those with the letter $\mathrm{B}$ will be given oxygen. Before and during the treatment period, the patient, the investigator, and the data collector are also blind to what is in each canister and what the letters $\mathrm{A}$ and $\mathrm{B}$ stand for. The rules were that the cessation of blinding would take place by the project manager only, after the completion of all the trials.

\section{Measurement}

The investigator will record participants' characteristics, demographic data (age, sex, nationality, weight, and height), and physiological parameters (pulse rate, blood pressure, and oxygen saturation). Other information regarding pain score, diagnosis of traumatic injury, total length of gas inhalation, analgesic prescription, adverse effects, satisfaction of patients and healthcare professionals, as well as the acceptance from patients will be recorded by the researcher.

Self-assessment of pain severity will be measured with the NRS. The NRS is a tool with great reliability and validity that is frequently used for assessing pain level from zero (painfree) to ten (worst pain intolerable) [31]. The physical parameters will be monitored via an electronic manometer (OMRON, HEM-7120) and OXIMETER (PC-60B). The evaluated pain score along with noninvasive monitoring of blood pressure, heart rate, and digital monitoring of oxygen saturation at baseline (T0) before the intervention, $5 \mathrm{~min}$ (T1), and $15 \mathrm{~min}$ (T2) after the beginning of the intervention, and at $5 \mathrm{~min}$ (T3) after the intervention.

Any observed adverse effects of the fixed nitrous oxide/oxygen mixture and oxygen will be carefully evaluated and recorded by the investigator after the beginning of the gas administration. The prospectively occurred adverse effects include gastrointestinal adverse effects (vomiting, nausea), respiratory adverse effects (oxygen desaturation which defined as pulse oximetric saturation $\leqq 94 \%$, arterial hypotension, and bradycardia), and any other discomfort (numbness, dizziness, drowsiness, oversedation, and headache) [32]. If any adverse effects take place, patients will be given inhaled oxygen and in $<5$ min the adverse effects will vanish. All severe adverse effects and management of them during the gas inhalation will also be noted.

Both patients' and healthcare providers' satisfaction with pain administration under the new analgesia will be investigated by a five-point satisfaction scale (5, very satisfied; 4 , satisfied; 3 , uncertain; 2 , dissatisfied; 1 , very dissatisfied) [33]. Moreover, the acceptance will be obtained by asking patients whether they would accept the same gas inhalation in case of another trauma with moderate to severe pain (yes / no). The satisfaction and the acceptance are recorded at $\mathrm{T} 3$.

The clinical demographic data, details of trauma type, and analgesic prescription will be obtained from medical records using a standardized case report form.

\section{Outcome measures \\ Primary outcome measure}

The primary outcome measure will be the level of pain relief after the initiation of the intervention, which is assessed and recorded by the data collector according to the pain level provided by patients using a self-assessment scale (NRS).

\section{Secondary outcome measures}

Secondary outcome measures include physiological parameters, adverse events, overall satisfaction from both 
patients and healthcare professionals, acceptance from patients, and total time of the gas administration.

\section{Sample size determination}

Based on our previous studies on cancer breakthrough pain and burn-dressing pain [32, 34], this study uses pain severity as the primary endpoint measure for sample size calculation. We used preliminary visits obtained in our ED for 20 patients and calculated the sample size at $5 \mathrm{~min}$ (T1) and $15 \mathrm{~min}$ (T2) after the beginning of intervention. It is observed that $65 \%$ of patients receiving premixed nitrous oxide/oxygen had pain relief at $\mathrm{T} 1$ compared with $8 \%$ of patients receiving oxygen (a decrease in pain intensity of at least $30 \%$ was recommended as the pain relief [35]). We found that $70 \%$ of patients in the experimental group experienced pain relief at T2 versus $10 \%$ in the control group. It aimed to determine a appropriate target sample size that would provide a $90 \%$ power $(\beta=0.10)$ for two-tailed testing with $5 \%$ type- 1 error rate of the measure. We separately calculated a minimum requirement of 30 patients or 24 patients for total with the formula [36, 37]. In practice, we finally decided on 90 samples (45 per group) to improve the power of this study.

\section{Recruitment}

In this trial, participants will be recruited at the ED of General Hospital of Ningxia Medical University. This medical center is the largest hospital in Ningxia Hui Autonomous Region. It is well-known in the northwestern region of China for its comprehensive disciplines, powerful technology, advanced medical equipment, outstanding specialties, and strong multidisciplinary advantages. Furthermoremore, according to the ED census data of 2016, there is a sufficient patient source in this hospital. Thus, in this selected clinical center, it is feasible to reach the target sample size.

\section{Participant retention and withdrawal}

As soon as a participant is enrolled, the research team are responsible for achieving a low rate of loss to intervention. Patients have the right to withdraw from the study at any time and this will not affect their subsequent treatment. The Data Monitoring Committee (DMC) will discuss and analyze the reason of dropout with the data collectors, which will be documented on a standardized pro forma.

\section{Data collection, management, and confidentiality}

All members involved in the research team will receive group training sessions before the study. Training will include study design (e.g. require double-blind), intervention process (e.g. inhaling gases via facemask), assessment of the outcome measures (e.g. standardized procedures to assess), and recorded data (e.g. training for the use of a unified data collection form in detail). Furthermore, the trained data collectors and investigators are fixed during the implementation of interventions and through the double-entry method for data quality control. The members of the DMC and the auditor will inspect this database regularly to promote data quality (see "Data monitoring" and "Auditing"). Using a Microsoft Access database (Microsoft Office 2010, Redmond, WA, USA) to accomplish all study data input.

Throughout the trial, participants are anonymized. All participants' personal information (e.g. name and patient identification number) will be kept in a separate locked cabinet and will be entered into the password-protected Microsoft Access database. Only research team members can access this personal data with reasonable request and consent of the project manager. A separate code, generated by pre-randomization, will enable anonymized data to be identified and this unique identifier will be maintained by the project manager. Anonymized trial data will be stored securely in another Microsoft Access database. The trial data collectors, the investigator, and the members of the DMC can access the trial data for the final statistical analysis.

\section{Data monitoring}

This trial will be overseen by a DMC, which is independent from the sponsor and competing interests. Members consisted of one clinician, two nurses working in the ED, one pain management specialist, and a senior academic statistician who acts as the committee's chair. The DMC will meet regularly to monitor the trial progress and guarantee protocol adherence. They are also responsible for checking for the reason of the participant withdrawal from this trial, assessing safety issues, and if there are any reasons that the trial should discontinue or make amendments.

\section{Auditing}

The trial funder will apply audits annually and inspect the source data to verify the accuracy, completion, validity, and safety of the data. The auditing will potentially include the utilization of funds, the essential documents, the trial progress, and the participants' medical records.

\section{Data analysis}

SPSS version 22.0 (Chicago, IL, USA) will be used to conduct the statistic analysis, initially according to the intention-to-treat principle. All patients randomized should be included in the analysis and missing data will be handled using multiple imputation. Descriptive statistics will be adopted to describe the population demographic data by medians (interquartile ranges [IQR]; min-max), means (standard deviations), and proportions 
(exact binomial 95\% confidence intervals [CIs]), as appropriate. The comparison of means will be assessed by Student's $t$ test or non-parametric test and using the Mann-Whitney test to compare means of continuous variables if applicable. Chi-squared tests or Fisher's exact test will be performed to compare the proportions of categorical variables. The analysis of physiological parameters and scores at baseline, T2, and T3 were performed by analysis of covariant (ANCOVA) adjusting for the respective baseline value on the two groups ("experimental" and "control"). We considered all $P$ values < 0.05 to be statistically significant.

\section{Ethics and dissemination}

The findings of this study will be shared with healthcare workers, patients, the general public, and relevant departments through open-access articles, public talks, conferences, and final reports. Any modifications of this protocol and changes to eligibility criteria or outcomes will be communicated with the DMC, clinicians, trial participants, and research ethics committee review board. There are no professional writers to be employed to complete the manuscript. Authorship eligibility guidelines which comply with the International Committee of Medical Journal Editors (ICMJE) guidelines [38] will be adhered to.

\section{Discussion}

The commitment to manage a patient's pain and relieve suffering is the foundation of a healthcare professional's obligation. Pain is not just a clinical symptom but also an evidence of potential pathology. In acute trauma environments, there is a temptation to ignore pain and its unique management, but all treatments lay the attention on the underlying pathology [24]. The challenge is to help health workers realize that symptoms and potential pathophysiology should go hand in hand.

In trauma patients, we usually give priority to injury mechanisms and assess the patient's signs of life, including the level of consciousness. Nevertheless, opioids may interfere with this assessment and necessitate continuous monitoring for some patients using these drugs [27, 39]. Opioids may also interact with other medicine used in the ED and should be administered cautiously [18]. It may be impractical to achieve completely painless in acute traumatic settings at present stage. However, by using widely used techniques, pain can be decreased to tolerable levels [24]. In fact, numerous studies compared the efficacy of nitrous oxide/oxygen with opioids, which showed that $50 \%$ nitrous oxide/oxygen decreased the overall opioids consumption in some foreign countries $[9,18,40-42]$. Furthermore, our previous studies have suggested that the appropriate concentration of diluted nitrous oxide managed by health workers for burn dressing and breakthrough pain are safe and effective [27, 32, 34].

To the best of our knowledge, this is the first randomized controlled trial in a busy emergency environment to evaluate the safety and analgesic effectiveness of the fixed nitrous oxide/oxygen mixture in patients with trauma in China. Pain is a natural accompaniment of acute injury to tissues, which is predictable in the case of acute trauma. If this treatment seems to be beneficial, this study could help to generate preliminary pain guidelines in patients with acute trauma and improve patients' overall satisfaction with ED. We believe that the results of this study could be considered as the introduction of pain management and be disseminated to international journals and conferences.

\section{Trial status}

Recruitment of patients began in November 2017.

\section{Additional files}

Additional file 1: SPIRIT 2013 Checklist: Recommended items to address in a clinical trial protocol and related documents. (DOC $115 \mathrm{~kb}$ )

Additional file 2: CONSORT 2010 checklist of information to include when reporting a randomized trial. (DOC $195 \mathrm{~kb}$ )

\section{Abbreviations}

ANCOVA: Analysis of covariant; CONSORT: Consolidated Standards of Reporting Trials; DMC: Data Monitoring Committee; ED: Emergency Department; ICMJE: International Committee of Medical Journal Editors; NRS: Numerical Rating Scale; SAF: Supervision Adherence Form

\section{Acknowledgements}

The research team would like to thank the financial support of Science and Technology Institute of Ningxia. This work is supported by Ningxia Medical University and the General Hospital of Ningxia Medical University. We thank the staff and patients in the Emergency Department who participated in the study. We also thank Aaita Cassidy for proofreading the manuscript.

\section{Funding}

This study was supported by the National Natural Science Foundation of China (Grant No. 81360182), the Ningxia Hui Autonomous Region Science and Technology Support Program (2018CMG03005, 2014-20). The funder provided financial support and will apply audits annually but had no role in the study design, execution, collection, management, analysis and interpretation of the data, writing of the report, or the decision to submit the report for publication. (Name: Science and Technology Institution of Ningxia Hui Autonomous Region, E-mail: Zyb5032354@163.com, Address: Ningxia Hui Autonomous Region, 239 West Road, State Power Building A, 809).

Availability of data and materials

After this study is complete, the final trial dataset and statistical codes will be available from the corresponding authors upon reasonable request, except for participants' personal information.

\section{Authors' contributions}

Conception and design: Y-XL, J-QY, and L-SY. Data collection: L-LG and Y-LD. Data analyses: $Q L, J-J Z$, and $Y$-LW. Coordination of the study implementation: L-SY, Y-YY, QL, KF, LM, Q-HW, and J-TB. L-LG wrote the first draft of the manuscript. $Y-X L$ and $J-Q Y$ revised the manuscript. All authors read and approved on the submitted version of the final manuscript. 


\section{Ethics approval and consent to participate}

Ethics approval of the study was obtained from Ningxia Medical University Ethics Review Committee (2014-179). Researchers introduced the specific intervention and their rights before the study to the included patients verbally and by informed consent form.

\section{Consent for publication}

Not applicable. We will obtain written consent for each participant before the intervention for any possible use of the relative information.

\section{Competing interests}

The authors declare that they have no competing interests.

\section{Publisher's Note}

Springer Nature remains neutral with regard to jurisdictional claims in published maps and institutional affiliations.

\section{Author details}

'School of Nursing, Ningxia Medical University, 1160 Shengli Street, Yinchuan 750004, China. ${ }^{2}$ Emergency Department, General Hospital of Ningxia Medical University, Yinchuan 750004, China. ${ }^{3}$ School of Basic Medical Sciences, Ningxia Medical University, 1160 Shengli Street, Yinchuan 750004, China. ${ }^{4}$ Institute of Nursing Research, Ningxia Medical University, 1160 Shengli Street, Yinchuan 750004, China. ${ }^{5}$ Department of Pharmacology, Pharmaceutical Institute of Ningxia Medical University, 1160 Shengli Street, Yinchuan 750004, China.

\section{Received: 15 November 2017 Accepted: 3 September 2018}

\section{Published online: 29 September 2018}

\section{References}

1. Ventafridda V, Saita L, Ripamonti C, De Conno F. WHO guidelines for the use of analgesics in cancer pain. Int J Tissue React. 1985;7:93-6.

2. Cordell WH, Keene KK, Giles BK, Jones JB, Jones JH, Brizendine EJ. The high prevalence of pain in emergency medical care. Am J Emerg Med. 2002;20: 165-9. https://doi.org/10.1053/ajem.2002.32643.

3. Berben SA, Meijs TH, van Dongen RT, Dongen RT, Vugt AB, Vloet LC, et al. Pain prevalence and pain relief in trauma patients in the accident and emergency department. Injury. 2008;39:578-85. https://doi.org/10.1016/j. injury.2007.04.013

4. Decosterd I, Hugli O, Tamches E, Blanc C, Houhsine E, Givel JC, et al. Oligoanalgesia in the emergency department: short-term beneficial effects of an education program on acute pain. Ann Emerg Med. 2007;50:462-71. https://doi.org/10.1016/j.annemergmed.2007.01.019.

5. Todd KH, Ducharme J, Choiniere M, Crandall CS, Fosnocht DE, Homel P, et al. Pain in the emergency department: results of the pain and emergency medicine initiative (PEMI) multicenter study. J Pain. 2007:8:460-6. https://doi. org/10.1016/j.jpain.2006.12.005.

6. Herres J, Chudnofsky CR, Manur R, Damiron K, Deitch K. The use of inhaled nitrous oxide for analgesia in adult ED patients a pilot study. Am J Emerg Med. 2016;34:269-70. https://doi.org/10.1016/j.ajem.2015.10.038.

7. Todd KH, Sloan EP, Chen C, Eder SC, Wamstad K. Survey of pain in etiology, management practices and patient satisfaction in two urban emergency departments. CJEM. 2002;4:252-6. https://doi.org/10.1017/ S1481803500007478

8. Wilson JE, Pendleton JM. Oligoanalgesia in the emergency department. Am J Emerg Med. 1989;7(6):620-3.

9. Aisuodionoe-Shadrach OI, Olapade-Olaopa EO, Soyannwo OA. Preoperative analgesia in emergency surgical care in Ibadan. Trop Doct. 2006;36:35-6.

10. Morgan-Jones R, Cutler L, Kaul S, Smith K. Patient satisfaction with preoperative analgesia in acute trauma. J R Coll Surg Edinb. 2000;45(6):371-2.

11. Silka $P$, Roth $M$, Geiderman J. Patterns of analgesic use in trauma in the ED. Am J Emerg Med. 2002;20:298-302. https://doi.org/10.1053/ajem. 2002.34195.

12. Fosnocht DE, Heaps ND, Swanson ER. Patient expectations for pain relief in the ED. Am J Emerg Med. 2004;22:286-8. https://doi.org/10.1016/j.ajem. 2004.04.011

13. Silka PA, Roth MM, Moreno G, Merrill L, Geiderman JM. Pain scores improve analgesic administration patterns for trauma patients in the emergency department. Acad Emerg Med. 2004;11:264-70. https://doi.org/10.1197/j. aem.2003.09.016
14. Nelson BP, Cohen D, Lander O, Crawford N, Viccellio AW, Singer AJ. Mandated pain scales improve frequency of ED analgesic administration. Am J Emerg Med. 2004;22:582-5.

15. Bartfield JM, Salluzzo RF, Raccio-Robak N, Funk DL, Verdile VP. Physician and patient factors influencing the treatment of low back pain. Pain. 1997:73:209-11.

16. Ricard-Hibon A, Chollet C, Saada S, Loridant B, Marty J. A quality control program for acute pain management in out-of-hospital critical care medicine. Ann Emerg Med. 1999;34:738-44. https://doi.org/10.1016/S01960644(99)70099-5.

17. Yuxiang $L$, Lingjun $Z$, Lu T, Mengjie $L$, Xing $M$, Fengping $S$, et al. Burn patients' experience of pain management: a qualitative study. Burns. 2012; 38(2):180-6. https://doi.org/10.1016/j.burns.2011.09.006.

18. Kariman $H$, Majidi A, Amini A, Dolatabadi AA, Derakhshanfar $H$, Hatamabadi $\mathrm{H}$, et al. Nitrous oxide/oxygen compared with fentanyl in reducing pain among adults with isolated extremity trauma: a randomized trial. Emerg Med Australas. 2011;23(6):761-8. https://doi.org/ 10.1111/j.1742-6723.2011.01447.x.

19. Hwang U, Richardson LD, Sonuyi TO, Morrison RS. The effect of emergency department crowding on the Management of Pain in older adults with hip fracture. J Am Geriatr Soc. 2006;54:270-5. https://doi.org/10.1111/j.15325415.2005.00587.x

20. Lin RJ, Reid MC, Liu LL, Chused AE, Evans AT. The Barriers to High-Quality Inpatient Pain Management: A Qualitative Study. Am J Hosp Palliat Care. 2015;32(6):594-9. https://doi.org/10.1177/1049909114530491.

21. Green CR, Anderson KO, Baker TA, Campbell LC, Decker S, Fillingim RB, et al. The unequal burden of pain: confronting racial and ehnic disparities in pain. Pain Med. 2003;4:277-94. https://doi.org/10.1046/j.1526-4637.2003.03034.x.

22. Tamayo-Sarver JH, Hinze SW, Cydulka RK, Baker DW. Racial and ethnic disparities in emergency department analgesic prescription. Am J Public Health. 2003;93:2067-73

23. Pollack CV Jr, Viscusi ER. Improving acute pain management in emergency medicine. Hosp Pract. 2015;43(1):36-45. https://doi.org/10.1080/21548331. 2015.1000794.

24. Aisuodionoe-Shadrach O. Acute trauma and preoperative pain. In: Kopf A, Patel NB, editors. Guide to pain Management in low-Resource Settings. Seattle: IASP; 2010. p. 115-8. http://www.doc88.com/p-9119407569103.html.

25. Fink WA. The pathophysiology of acute pain. Emerg Med Clin North Am. 2005;23(2):277-84

26. Emmanouil DE, Quock RM. Advances in understanding the actions of nitrous oxide. Anesth Prog. 2007:54:9-18.

27. Maslekar S, Gardiner A, Hughes M, Culbert B, Duthie GS. Randomized clinical trial of Entonox versus midazolam-fentanyl sedation for colonoscopy. $\mathrm{Br}$ J Surg. 2009;96:361-8.

28. Li YX, Tang L, Yu JQ, Dai XY, Zhou WF, Zhang WN, et al. Analgesia effect of a fixed nitrous oxide/oxygen mixture on burn dressing pain: study protocol for a randomized controlled trial. Trials. 2012;13:67. http://www.trialsjournal. com/content/13/1/67.

29. Masood J, Shah N, Lane T, Andrews H, Simpson P, Barua JM. Nitrous oxide (Entonox) inhalation and tolerance of transrectal ultrasound guided prostate biopsy: a double-blind randomized controlled study. J Urol. 2002;168:116-20. https://doi.org/10.1097/01.ju.0000057805.61396.b0

30. Chan AW, Tetzlaff JM, Altman DG, Laupacis A, et al. SPIRIT 2013 statement: defining standard protocol items for clinical trials. Ann Intern Med. 2013;158 200-7. https://doi.org/10.7326/0003-4819-158-3-201302050-00583.

31. Annequin D, Carbajal R, Chauvin P, Gall O, Tourniaire B, Murat I. Fixed 50\% nitrous oxide oxygen mixture for painful procedures: a French survey. Pediatrics. 2000;105:E47

32. Liu Q, Wang $Y$, Luo XJ, Wang NJ, Chen $P$, Jin $X$, et al. A fixed inhaled nitrous oxide/oxygen mixture as an analgesic for adult cancer patients with breakthrough pain: study protocol for a randomized controlled trial. Trials. 2017;18(1):13. https://doi.org/10.1186/s13063-016-1739-9.

33. Juang CM, Yen MS, Horng HC, Cheng CY, Yu HC, Chang CM. Treatment of primary deep dyspareunia with laparoscopic uterosacral nerve ablation procedure: a pilot study. J Chin Med Assoc. 2006;69(3):110-4.

34. Li YX, Han WJ, Tang HT, Wu YS, Tang L, Yu JQ, et al. Nitrous oxide-oxygen mixture during burn wound dressing: a double-blind randomized controlled study. CNS Neurosci Ther. 2013;19(4):278-9. https://doi.org/10. 1111/cns.12061.

35. Salas $S$, Auquier $P$, Duffaud F, Garnier SR, Deschamps M, Honoré $S$, et al. Efficacy of lidocaine in patients receiving palliative care with 
opioidrefractory cancer pain with a neuropathic component: study protocol for a randomized controlled study. Trials. 2014;15:318. https://doi.org/10 1186/1745-6215-15-318.

36. Chow SC, Shao J, Wang H, Lokhnygina Y. Sample size calculation in clinical research. 3rd ed. New York: Marcel Dekker; 2003.

37. Casagrande JT, Pike MC, Smith PG. An improved approximate formula for calculating sample sizes for comparing two binomial distributions. Biometrics. 1978;34:483-6.

38. ICMJE. http://www.icmje.org/recommendations/browse/roles-andresponsibilities/defining-the-role-of-authors-and-contributors.html. Accessed 14 Aug 2017.

39. Sweetman SC. Martindale: the complete drug reference. 34th ed. London: Pharmaceutica.l; 2005. p. 71-5.

40. Abdelkefi A, Abdennebi YB, Mellouli F, Othman TB, Torjman L, Ladeb S, et al. Effectiveness of fixed $50 \%$ nitrous oxide oxygen mixture and EMLA cream for insertion of central venous catheters in children. Pediatr Blood Cancer. 2004:43(7):777-9. https://doi.org/10.1002/pbc.20186.

41. Descamps MJ, Gwilym S, Weldon D, Holloway V. Prospective audit of emergency department transit times associated with entonox analgesia for reduction of the acute, traumatic dislocated shoulder. Accid Emerg Nurs. 2007;15:223-7. https://doi.org/10.1016/j.aaen.2007.07.008.

42. Hoeffe J, Trottier ED, Bailey B, Shellshear D, Lagace M, Sutter C, et al. Intranasal fentanyl and inhaled nitrous oxide for fracture reduction: the FAN observational study. Am J Emerg Med. 2017;35:710-5. https://doi.org/10. 1016/j.ajem.2017.01.004.

Ready to submit your research? Choose BMC and benefit from:

- fast, convenient online submission

- thorough peer review by experienced researchers in your field

- rapid publication on acceptance

- support for research data, including large and complex data types

- gold Open Access which fosters wider collaboration and increased citations

- maximum visibility for your research: over $100 \mathrm{M}$ website views per year

At $\mathrm{BMC}$, research is always in progress.

Learn more biomedcentral.com/submissions 